"Über das Leben des Hörers reden" oder: Lebenswelt als Deutungshorizont der Predigt

Kunz, Ralph

DOI: https://doi.org/10.1515/9783110247671.223

Posted at the Zurich Open Repository and Archive, University of Zurich ZORA URL: https://doi.org/10.5167/uzh-55100

Book Section

Published Version

Originally published at:

Kunz, Ralph (2011). "Über das Leben des Hörers reden" oder: Lebenswelt als Deutungshorizont der Predigt. In: Klie, Thomas; Kumlehn, Martina; Kunz, Ralph; Schlag, Thomas. Lebenswissenschaft Praktische Theologie?! Berlin/New York: De Gruyter, 223-251.

DOI: https://doi.org/10.1515/9783110247671.223 


\title{
„Über das Leben des Hörers reden“ oder: Lebenswelt als Deutungshorizont der Predigt
}

\author{
Ralph Kunz
}

\section{1. Über das Leben reden}

\subsection{Trivial und gehaltvoll}

Ernst Lange hat den eingängigen Satz geprägt, Predigen sei „mit dem Hörer über sein Leben reden" ${ }^{\prime \prime}{ }^{1}$ Das leuchtet ein. Wer statt über das Leben über die Köpfe seiner Hörer hinweg redet, redet in den Wind oder an die Wand. Nur, ist das gemeint, wenn von der Lebenswelt als Deutungshorizont der Predigt die Rede ist? Das lebensweltliche Postulat wäre dann nicht mehr als ein gescheit klingendes Kürzel für eine triviale Erkenntnis, die zu anderen Zeiten von Anknüpfung, Praxisbezug oder Alltagsrelevanz hätte reden lassen.

Nun war Langes Postulat durchaus provokativ gemeint und tatsächlich ein Affront gegenüber einer Homiletik, die die Aufgabe der Theologie primär als Wort Gottes verstand, also dezidiert nicht über das Leben des Hörers, sondern von Gott reden wollte. Um nicht in alte Grabenkämpfe zurückzufallen, sei zu dieser Auseinandersetzung bemerkt, dass Lange sich dafür interessiert, wie das Leben des Hörers mit dem Leben Gottes zusammenhängt oder - näher an seiner Diktion - wo die Rede von Gott in der gegenwärtigen Lebenswelt relevant wird. Das ist predigttheologisch alles andere als trivial.

Wolf-Eckart Failing hat der Praktischen Theologie schon vor zehn Jahren ins Stammbuch geschrieben, dass es darum gehe, „im Rahmen der Praktischen Theologie einen thematisch gehaltvollen LebensweltBegriff $\mathrm{zu}$ gewinnen, der nicht rhetorisch belanglos wird und als Allerwelts-Begriff banal abgleitet “2. Ein wichtiges Fanal in diesem Zu-

1 Ernst Lange, Predigen als Beruf, Stuttgart 1976, 58.

2 Wolf-Eckart Failing, Lebenswelt und Alltäglichkeit in der Praktischen Theologie, in: Ders./Heimbrock, Gelebte Religion wahrnehmen. Lebenswelt - Alltagskultur - Religionspraxis, Stuttgart/Berlin/Köln 1998, 145-176, 175. 
sammenhang ist die Losung von der Rettung der Phänomene. ${ }^{3}$ Denn der phänomenologische Ansatz bündelt die ambitionierte Diskussion, die mit dem und zum Teil gegen den Begriff ,Lebenswelt' geführt wird. Die Phänomenologie hat den Lebenswelt-Begriff vor dem Abgleiten in die Belanglosigkeit gerettet, indem sie dazu anstiftete, mit Leben über Gott zu reden.

\subsection{Aufwand und Auftrag}

Wer Lebenswelt gehaltvoll zur Sprache bringen will, stößt unweigerlich auf das Paradox der Phänomenologie. Der Weg zu den "Sachen“ ist gepflastert mit Gedanken. Und wer überlegt ans Werk geht und sich Gedanken macht über den Weg zum Phänomen, kommt zwangsläufig zum Logos, auf die Sprache, die bedenkt, beschreibt und bespricht, was Sache ist. Der Weg zu den Sachen ist ein hermeneutisch aufwändiges Hin und Zurück. ${ }^{4}$

Zum Aufwand kommt ein Auftrag. Theologie versteht sich aufgrund ihres Lebensbezugs als praktische Wissenschaft. Der Bezug zum Leben leistet eine Nachdenklichkeit, die zum Leben gehört, sich Gott verdankt und darum auf Gott als Quelle des Lebens zurückkommt oder - mit Paulus gesprochen - sich Christus unterstellt (2. Kor 10,5). So bringt Luther es auf den Punkt: "Vera theologia est practica et fundamentum eius est Christus, cuius mors fide apprehenditur". ${ }^{5}$ Auch ein zweiter Grundsatz Luthers, "sola experientia facit theologum" "6, begreift Praxis als gehaltvolles Leben coram deo.

Wenn der Weg von den Sachen und zurück ein Unterwegssein mit Gott bedeutet, muss die Rede von der Lebenswelt als Deutungshorizont der Predigt den hermeneutischen Aufwand und den keryg-

3 Der Kampfruf „Rettet die Phänomene!“ stammt vom Physikdidaktiker Wagenschein. Er lässt etwas vom Pathos des gelebten Lebens spüren, der schon in Husserls "Ruf zu den Sachen“ anklingt. Vgl. dazu Martin Wagenschein, "Rettet die Phänomene!“, in: Ders., Erinnerungen für Morgen. Eine pädagogische Autobiographie, Weinheim/Basel 1983, 135-153.

4 "Zu den Sachen und zurück" heisst der sinnige Titel eines Sammelbandes mit Aufsätzen von Hans Blumenberg (Stuttgart 2002). Hans Blumenbergs Denken bewegt und behauptet eine Position zwischen Husserl und Wittgenstein: zwischen den Sachen und der Klärung der Sprache, die zur Sache kommt.

5 Luther fährt fort: „Speculativa igitur theologia, die gehört in die Hölle zum Teufel.“ Zitiert aus Gerhard Ebeling, Luthers Seelsorge. Theologie in der Vielfalt der Lebenssituationen an seinen Briefen dargestellt, Tübingen 1997, 3.

6 Vgl. Martin Luther, WA TR 1,16,13; 312,11.5; 385,5. Die Belege sind zitiert aus Gerhard Ebeling, Evangelische Evangelienauslegung, Tübingen 1991, 12. 
matischen Auftrag verknüpfen. Ihre Nachdenklichkeit dient dem Ereignis der Verkündigung ubi et quando visum deo. Nicht alle Praktischen Theologen ziehen diese Konsequenz. Ich ziehe sie. Denn „es geht darum", um es mit einer pointierten Formulierung Henning Schröers zu sagen, "was geht, wenn Gott kommt. ${ }^{47}$

\subsection{Klärungsbedarf}

Predigtlehre heißt, sich Gedanken zu machen, wie Kommunikation des Evangeliums gelingt. Gelingen heißt, zur Sache und zu den Sachen zu kommen. Damit ist das konkrete Ineinander von Gott und Leben gemeint, das Ernst Lange mit Relevanz umschrieben hat. Wenn die Relevanz der Kanzelrede eingeklagt wird, muss freilich auch mit irrelevanten Predigten gerechnet werden. Lange warnte vor Predigten, die Gott so vehement besprechen, dass sie das Leben der Hörer verpassen. Man soll die andere Gefahr nicht vergessen, dass man beim Vorstoß in die Lebenswelt Gott verpassen kann. Eingedenk des Risikos, dass das Leben oder Gott oder beides verpasst werden kann, ist nicht nur ein gemeinsames Anliegen, sondern auch ein gemeinsamer theologischer Ansatzpunkt der hermeneutischen und phänomenologischen Homiletik zu erkennen: Es geht darum, Wirklichkeit so wahrzunehmen, dass sich Gott zu Wort melden kann und die Rede von Gott so zu gestalten, dass sich die Wahrnehmung der Welt erhellt.

Was meint die Rede von der Lebenswelt als Deutungshorizont der Predigt? Ich sehe dreifachen Klärungsbedarf:

- Klärungsbedürftig ist die philosophische Basis der Rede von der thematisch gehaltvollen Lebenswelt als Deutungshorizont der Predigt.

- Theologischen Klärungsbedarf sehe ich hinsichtlich der Forderung, sich an diesem Horizont zu orientieren.

- Klärungsbedarf sehe ich hinsichtlich der Konsequenzen für die Gestaltung einer religiösen Rede, die der Herausforderung der Lebensweltorientierung rhetorisch gerecht wird.

Das sind zu große Aufgaben für einen kurzen Beitrag. Ich möchte dennoch wagen, in einem ersten Schritt den Bogen von der hermeneutischen zur phänomenologischen Homiletik zu schlagen (2.). Nach

7 Henning Schröer, Die Bedeutung der Phänomenologie für die Konstitution Praktischer Theologie, in: Wolf-Eckart Failing/Hans-Günter Heimbrock/Thomas A. Lotz, Religion als Phänomen, Berlin 2001, 46-59, 54. 
der knappen Skizze der gegenwärtigen Theoriediskussion konzentriere ich mich auf zwei Beiträge: Albrecht Grözingers Versuch, die Welten der Predigt zu ordnen (3.), und den programmatischen Entwurf einer phänomenologisch fundierten Praktischen Theologie, vorgelegt von Hans-Günter Heimbrock und Wolf-Eckart Failing (4.). Grözingers Welten-Modell relativiert eine exklusive Lebensweltorientierung dadurch, dass es auf Wechselwirkungen mit anderen Welten aufmerksam macht. Failing und Heimbrock arbeiten an einer thematisch gehaltvollen Lebenswelt. Ziel meiner Überlegungen ist eine kritische Auseinandersetzung mit dem Anspruch der Lebensnähe in der hermeneutischen und phänomenologischen Homiletik (5.). Dabei soll auch die (vermeintlich) überwundene Position der kerygmatischen Homiletik ihr kritisches Potential entfalten. Predigen, so meine Schlussthese, interpretiert Leben im Deutungshorizont der Glaubensfeier.

\section{Knappe Skizze der gegenwärtigen homiletischen Diskussion}

Kein anderer Theologe hat die homiletische Diskussion in der zweiten Hälfte des 20. Jahrhunderts so geprägt wie Ernst Lange. ${ }^{8}$ Die zitierte Formel „mit dem Hörer über sein Leben reden“ expliziert Lange selbst als ein Reden über die Erfahrungen und Anschauungen, Hoffnungen und Enttäuschungen, Erfolge und Misserfolge, Aufgaben und das Schicksal des Hörers. Predigen ist Reden über die Verantwortung des Hörers in seiner Welt, über die Bedrohungen und die Chancen seines Daseins. Predigt soll die Deutungskompetenz der Hörer fördern. Es soll ihnen ein Licht aufgehen im Gottesdienst, ein Licht, das ihren Alltag aufklärt.

Originell ist das nicht. Doch Langes beherzte Zuwendung zum Empfänger und Adressaten der Botschaft markierte damals, als er sein Plädoyer vortrug, eine Umorientierung der textorientierten zur lebensweltorientierten Homiletik. Zu Recht gibt Albrecht Grözinger zu bedenken, dass man aber Lange gründlich missverstanden hätte, wenn man meint, er würde "den lebensweltlichen Binnenhorizont zur thematischen Mitte der Predigt erheben. ${ }^{\prime 9}$ Es geht um das menschliche Leben im Licht der Christusverheissung: den Hörer vor Gott. ${ }^{10}$

\footnotetext{
8 Albrecht Grözinger, Homiletik, Gütersloh 2008, 70-74.

9 A.a.O., 72.

10 Ernst Lange, Predigen als Beruf, 58.
} 
Man beginnt einen kurzen Abriss der gegenwärtigen Homiletik auch deshalb am besten mit Langes hermeneutischer Predigttheorie, weil das Verständnis seines Ansatzes der Diskussion ebenso wichtige Impulse verliehen hat wie das Missverständnis. Ich denke an Bohrens Versuch, den Gottesbezug wieder vor den Hörerbezug zu stellen, also nicht nur mit dem Hörer über sein Leben zu reden, sondern Gott als ersten Hörer wahrzunehmen. ${ }^{11}$ Weiterführend war und ist auch die rezeptionsästhetische Wahrnehmung der Predigtaufgabe nach dem Vorbild des „Offenen Kunstwerkes“, die - auch im Namen der Hörer gegen eine pädagogische Instrumentalisierung der fremden Textwelt protestierte.

$\mathrm{Ob}$ man die theologische und semiotische Kritik als Weiterentwicklung oder als Bruch mit der hermeneutischen Homiletik interpretieren will, hängt wohl davon ab, mit welchen Prämissen man über Predigt nachdenkt. Versteht man unter der Kommunikation zwischen Prediger und Hörer die Bemühung, der Bewegung des Textes folgend eine deutende Bewegung beim Hörer auszulösen, hat dies schon Ernst Lange gesagt. Wenn von einem Paradigmenwechsel die Rede sein soll, wäre der innerhalb einer weit gefassten hermeneutischen Praxistheorie zu verorten: weg von einer einseitigen auf Texthermeneutik fixierten Perspektive der Produktion hin zu einer kulturhermeneutisch befreiten Perspektive der Wechselwirkungen zwischen Produktion und Rezeption. ${ }^{12}$

Wenn auch die jüngere Theoriegeschichte im Sinne einer kontinuierlichen Entwicklung in Richtung einer erweiterten Predigthermeneutik gedeutet werden kann, sind doch die markanten Akzentverschiebungen nicht zu übersehen, die nach dem ,linguistic turn' der Diskussion eine neue Richtung verliehen haben. Kommunikationstheoretisch war die ästhetische Weitung mit einer kritischen Distanz zum naiven Vorbild einer 1:1-Übereinstimmung zwischen Sender und

11 Gott der erste Hörer ist ein Mittler zwischen Mensch und Mensch. Vgl. Rudolf Bohren, Predigtlehre, München ${ }^{4} 1980,456$. Zu Bohrens Homiletik vgl. Jantine Nierop, Die Gestalt der Predigt im Kraftfeld des Geistes. Eine Studie zu Form und Sprache der Predigt nach Rudolf Bohrens Predigtlehre, Wien/Zürich/Berlin 2008.

12 Dazu Jan Peter Grevel, Die Predigt und ihr Text. Grundlegung einer hermeneutischen Homiletik, Neukirchen-Vluyn 2002, 51: „Hält man sich [...] diejenigen homiletischen Entwürfe vor Augen, die im Kern noch ganz den Vergegenwärtigungsstrategien der ,hermeneutischen Theologie' vertrauen, so dürfte der Nachvollzug des ,linguistic turn' für die Homiletik tatsächlich einen Paradigmenwechsel herbeigeführt haben, der [...] zur Auseinandersetzung mit der Semiotik Ecos geführt hat. " Ob der Paradigmenwechsel zu Recht von einer posthermeneutischen Theologie sprechen lässt, wage ich zu bestreiten. Vgl. dazu Marcus Döbert, Posthermeneutische Theologie. Plädoyer für ein neues Paradigma, Stuttgart 2008. 
Empfänger verbunden. Das war eine entscheidende Weichenstellung!13 Eindeutigkeit kann nicht das Ziel einer Predigt sein, wie das Wilfried Engemann in seinem homiletischen Ouevre auf erhellende Weise erklärt. ${ }^{14}$ Das Abrücken von der Eindeutigkeit hat andere Verständigungsstrategien in den Vordergrund gerückt. Mit der Wahrnehmung der Predigt als Sprechakt und als eigene Sprachwelt kommen ihre Rhethorizität, ihre Symbolizität und ihre Theatralizität in den Blick.

Darauf läuft mein kurzer tour d'horizon hinaus: Zentrale Einsichten der ästhetischen Rezeption, die Mehrdeutigkeit des Bibeltextes und die sukzessive Hermeneutik der religiösen Rede, haben das Gespräch mit dem Hörer nicht ersetzt. Sie haben es aber entspannt und vom Anspruch der Anwaltschaft entlastet, der bei Lange so drückend und allgegenwärtig spürbar war..$^{15} \mathrm{Um}$ es mit einer Formel der dramaturgischen Homiletik zu sagen: Die Lebensweltorientierung der Prediger zeigt sich in erster Linie an der sprachsensiblen Gestaltung und Inszenierung des homiletischen Akts und nicht daran, dass einer auf "Gott komm raus" ein Gespräch mit dem Hörer inszeniert. Dabei geht es einer hermeneutisch erweiterten und reflektierten Predigttheorie immer auch um die wechselseitigen Bezüge, die zwischen der Lebenswelt der Hörer und dem Innenraum des Predigers, der Textwelt und der Glaubenswelt der Kirche in der Predigtwelt aufgenommen und wahrgenommen werden.

\section{Welten der Predigt}

\subsection{Die drei Welten der Predigt}

Auf diese Interdependenzen hat Albrecht Grözinger in hellsichtiger Weise hingewiesen. ${ }^{16}$ Die Aufgabe der Predigt sei es, einen Raum zu eröffnen, in dem sich Hörer und Hörerinnen bewegen können. Dieser Raum erwachse aus den Erfahrungen anderer Räume, die allerdings

13 Vgl. dazu Grözinger, Homiletik, 80-87.

14 Vgl. Wilfried Engemann, Semiotische Homiletik. Prämissen, Analysen, Konsequenzen, Tübingen 1993; Ders., Theologie der Predigt. Grundlagen - Modelle - Konsequenzen, Leipzig 2001; ders., Einführung in die Homiletik, Tübingen 2002.

15 In gewisser Weise gilt das auch für den Umgang mit dem Text und seine Befreiung aus dem Klammergriff des „Skopus“. Vgl. dazu Grevel, Die Predigt, 255.

16 Ich beziehe mich auf Albrecht Grözinger, Toleranz und Leidenschaft. Über das Predigen in einer pluralistischen Gesellschaft, Gütersloh 2004, 109-136 und Ders., Homiletik, Gütersloh 2008, 99-176. 
derart komplex sind, dass sie als ,eigene Welten' angesprochen werden können. ${ }^{17}$

Grözinger spricht vom Prediger als Wanderer zwischen drei Welten: der Welt des Textes, der Welt seiner Hörer und Hörerinnen und der Welt seiner eigenen Subjektivität. Das Problem, das mit dem WeltenModell bearbeitet werden soll, lässt sich so skizzieren: Der Prediger kann sich in jeder der drei Welten verlaufen und den Überblick verlieren, gerade weil er so viel über diese Welten weiß. Die WeltMetapher erhöht also das Bewusstsein für die hermeneutische Herausforderung der homiletischen Deutungsarbeit, auf die schon das "homiletische Dreieck" aufmerksam machte. ${ }^{18}$ Es bietet außerdem die Möglichkeit, die Räume der Wahrnehmung, die durch die Predigt eröffnet werden, je für sich abzuschreiten und theoretisch auszuleuchten. Insofern verlässt das Welten-Modell die sprach- und kommunikationstheoretische Logik ${ }^{19}$ des homiletischen Dreiecks und ersetzt es durch ein wesentlich komplexeres Modell. ${ }^{20}$

\subsubsection{Die Textwelt}

Wenn eingangs Langes Ansatz als Provokation der kerygmatischen Homiletik vorgestellt wurde, ist die Vorstellung, dass die Lebenswelt, das Ich des Predigers und der Text der Predigt Welten auf der gleichen Stufe sein sollen, nicht minder provokativ. Dass man sich in der Welt und im Ich verirren kann, mag wohl sein. Aber woran, wenn nicht an

17 Grözinger, Toleranz und Leidenschaft, 111f. und Ders., Homiletik, $99 \mathrm{f}$.

18 Das Vorbild für das „homiletische Dreieck“ liefert Schleiermacher, Praktische Theologie nach den Grundsätzen der evangelischen Kirche in Zusammenhange dargestellt, aus Schleiermachers handschriftlichem Nachlasse und nachgeschriebenen Vorlesungen hrsg. von Jacob Frerichs, Berlin 1850, 248, wenn er geistliche Rede durch den Doppelbezug auf Gemeinde und Text charakterisiert: „Der Geistliche hat zwei Gesichtspunkte: er geht auf der einen Seite auf den Zusammenhang zurück der in seiner Schriftstelle stattfindet; aber indem er seine Gemeinde im Auge hat, hat er darauf zu sehen was diese gewohnt ist, und weil er in einer freien Richtung sich befindet, so muss ihm gegenwärtig sein, wie die Gemeine über den Gegenstand zu denken pflegt. Das Verfahren ist seiner Natur nach ein Dialogisches; es ist ein Dialog mit seiner Schriftstelle, die er fragt und die ihm antwortet, und mit seiner Gemeine."

19 Vgl. dazu Karl Wilhelm Dahm, Hören und Verstehen. Kommunikationssoziologische Überlegungen zur Predigtnot, in: Ders., Beruf: Pfarrer. Empirische Aspekte von Kirche und Religion in unserer Gesellschaft, München 1971, 218-244. Er spricht kommunikationslogisch von Redner, Rede und Hörer.

20 Ich folge hier der Darstellung in „Toleranz und Leidenschaft“. Das Modell wurde im Lehrbuch „Homiletik“ zwar an manchen Stellen verfeinert, aber die Pointen, die mir wichtig sind, sind in „Toleranz und Leidenschaft" deutlicher zu erkennen. 
der Heiligen Schrift, orientiert sich der Prediger. So ruft der fromme Protestant und hat das Modell noch nicht begriffen.

Denn auch in der Welt der Bibel herrscht zunächst die Unübersichtlichkeit. Das Problem der Orientierungslosigkeit hat jeder Lektor. Denn "kein endlicher Textleser hält die Unendlichkeit der Textwelten aus. ${ }^{\text {"21 }}$ Grözinger identifiziert den Kanon als Deutungshorizont der Bibel und hebt die eröffnende und deutungsproduktive Funktion der kanonischen Begrenzung hervor. Denn am Anfang des christlichen Kanons stand der Plural.

„Der Plural, der darin bestand, dass eine alte Religion und eine neu entstandene Religion sich eine gemeinsame Textwelt teilten, mit all den Auseinandersetzungen, die aus diesem Raum-Teilen entstehen mussten. ${ }^{\prime 22}$

Der Kanon schützt und bewahrt darum die Pluralität der Textwelt; er ist der "plurale Schutzraum der Textwelten, die von dem biblischen Gott und seiner Geschichte mit der Menschheit erzählen. “23 Grözinger rät deshalb der Predigerin, die Textwelt der Bibel zu bewohnen, durch sie $\mathrm{zu}$ schreiten, sie zu erkunden und sich an ihr mit unverbrauchbarem Respekt abzuarbeiten. ${ }^{24}$ Das Votum für den Überschuss und Eigenwert des Textes ist immer verbunden mit einer Absage an eine eindeutige und eingleisige Theologie.

„Es gibt eben nicht das christliche Menschenbild, es gibt auch nicht die christliche Ethik, und ebenso wenig gibt es die christliche Antwort auf ein bestimmtes Problem. ${ }^{25}$

\subsubsection{Die Lebenswelt der Hörer}

Eine ähnliche Spannung konstatiert Grözinger auch in der zweiten Welt. Einerseits muss jede Predigt an der biographischen Geländeerkundung partizipieren, „wenn sie die Menschen als ihre Hörerinnen und Hörer in ihrer je eigenen Biographie ansprechen will.“26 Aber das ist kein Spaziergang. Die biographische Erkundung ist in der Postmoderne riskanter geworden. Grözinger verweist auf den Verlust der

21 Grözinger, Toleranz und Leidenschaft, 113.

22 A.a.O., 115.

23 A.a.O., 117.

24 A.a.O., 121. In der eigenartigen Spannung von Gesamtbild und perspektivischer Verfremdung durch den Eigensinn des Textes, entsteht, was Lange den Widerstand des Textes gegen die Tradition genannt hat.

25 Grözinger, Toleranz und Leidenschaft, 117.

26 A.a.O., 122. 
Musterlebensläufe. Wir stehen am fließenden Übergang der Zeit der weithin unbestritten gültigen Musterlebensläufe und der Zeit, in der es solche Musterlebensläufe kaum noch geben wird. ${ }^{27}$ Beweglicher und bunter sei alles geworden, aber auch anstrengender. Die Individualisierung erlege dem einzelnen Menschen ein immer größeres Maß an Interpretations- und Integrationsleistungen auf. Dabei gebe es keine verlässliche Grammatik oder selbstverständliche Symbol- oder Bildwelt, bei der die Erfindung des eigenen Lebens Unterstützung finden könnte. Die alten großen Erzählungen seien ja verschwunden. ${ }^{28}$

\subsubsection{Das Ich des Predigers}

Allerdings seien auch postmoderne Subjekte, wenn sie Identitäten bilden, auf Erzählungen angewiesen, die ihnen helfen, sich in der Welt heimisch zu fühlen. Früher habe der Mythos eine solche Beheimatung geleistet. Dass die Kraft der großen Erzählungen geschwunden sei, heiße aber nicht, dass die beheimatende Funktion der Geschichten verloren gegangen wäre. Erzählen mache Leben begehbar, Geschichten beheimaten in der Welt. Darum geht es: die Verbindung von Menschengeschichte und Gottesgeschichte zu finden.

So könnte man Grözingers Anliegen, das Lebensweltliche zu erkunden, zusammenfassen. Gleichzeitig warnt er:

„Aber diese Geschichten können nicht mehr die Form der Grosserzählung, also die Form einer geschlossenen Weltdeutung, annehmen ... Auch das Christentum hat sich mit diesem gross-erzählerischen Gewand gekleidet. Heute stehen wir vor der Aufgabe, dieses gross-erzählerische Gewand abzuwerfen. Christentum wird es in der Postmoderne zunehmend mit den kleinen Geschichten zu tun haben, die sich nicht ohne weiteres zu einer Gross-Erzählung runden. Die kleinen Geschichten des vielfältigen und heterogenen Alltags, des schwachen Subjekts. Und die kleinen Geschichten der biblischen Überlieferung, in der Form und in der Brisanz abseits ihrer gross-erzählerischen Vereinnahmung. Damit sind wir vor eine spannende, nicht zuletzt theologisch qualifizierte, Herausforderung gestellt. Nämlich uns in unserem Predigen auf diesen heute - wie ich meine - notwendigen Transformationsprozess von der Identitätsbildung im Kontext von GrossErzählungen hin zu einer Identitätsbildung in kleinen Stories [...] einzulassen. ${ }^{229}$

27 A.a.O., 125.

28 A.a.O., 126.

29 A.a.O., 128. 
Wie aber kommen diese beiden Welten - Textwelt und Lebenswelt der Hörer - zusammen? Dann am besten, „wenn die Subjektivität des Predigers und der Predigerin in der Predigt erkennbar wird. " ${ }^{30}$ Das Ich ist die dritte Welt. Denn konkret wird die Gottesgeschichte immer nur in der individuellen und unverwechselbaren Lebensgeschichte des Predigers. Es gibt kein distanziertes Reden über Gott. Unter der Absehung von der eigenen Subjektivität kann die Verbindung von Text und Leben nicht gelingen. Predigt ist Zeugnis, also kein Subjektivismus; denn "das, was ich sage, ist nicht ein Reden über etwas, sondern das, was ich sage, ist durch mich hindurch gegangen." ${ }^{31}$ Im Durchgang durch die Subjektivität findet das Religiöse eine Gestalt, die wiederum Gestalt stiften kann.

\subsubsection{Die Schwellen-Predigt}

Mit Kanon, Story und Subjektivität werden die Deutungshorizonte der Textwelten, Lebenswelten und der Predigerexistenz zueinander ins Verhältnis gesetzt, in der Predigt werden sie miteinander ins Spiel gebracht und kunstvoll verknüpft. Das Resultat nennt Grözinger eine Schwellen-Predigt. Denn Aufgabe der Predigt sei es, die Schwelle zu gestalten, aber sie zu überschreiten, bleibe dem Hörer vorbehalten. Mit der Raummetaphorik gesprochen: Menschen werden eingeladen, eine Sprachwelt zu betreten, die ihnen einen Deutungshorizont für ihre Lebenswelt offeriert. Und weil der Prediger nicht mit einer homogenen Gruppe von Gottesdienstbesuchern rechnen könne, müsse er die Menschen, die diese Schwelle überschreiten sollen, kennen. ${ }^{32}$

Aber lässt sich denn diese heterogene Gruppe überhaupt noch mit einer Predigt ansprechen? Grözinger meint:

„Je mehr eine Predigt die pluralen Potentiale in sich birgt, die die drei Welten, die die Predigt konstituieren, mit sich bringen, um so eher wird eine solche Predigt dann auch den pluralen Welten gerecht, die die Menschen mit sich bringen, wenn sie eine Predigt hören. “33

Gefordert wird sprachliche Sensibilität und Klarheit und verbannt werden Eindeutigkeiten, die von der Kanzel verordnet werden. Predigt eröffnet Räume, in denen Orientierung und Lebensgewissheit ent-

\footnotetext{
30 A.a.O., 129.

31 A.a.O., 131.

32 A.a.O., 132.

33 A.a.O., 135.
} 
stehen könnten. ${ }^{34}$ Wenn sie aber mehr sein will als Schwellenmarkierung, so die Behauptung, habe sich schon um ihre Wirkung gebracht.

\subsection{Relativierung der Lebenswelt als Deutungshorizont}

Was ist das Plus des Weltenmodells gegenüber Lange? Es verspricht einen Gewinn an Gelassenheit, Anmut und Toleranz! Eine sprach- und wirklichkeitssensibel gestaltete Kanzelrede, die Bezug nimmt auf den Hörer, beschreibt Welt und schreibt nicht vor, wie sie gedeutet werden muss. Sonst fliehen die Hörer. Die Charakterisierung der Predigtarbeit als Wanderung, Erkundung und Durchschreitung von Räumen und Welten relativiert demnach die Rede vom Deutungshorizont der Lebenswelt, ohne in Abrede zu stellen, dass dieser Horizont bei der Deutungsarbeit gegenwärtig sein muss. Insofern knüpft Grözinger bei Lange an, ersetzt aber das streitbare Plädoyer des Anwalts, der für die Relevanz des Evangeliums für das Leben seiner Hörer zeugt, durch eine anmutige Rede eines wohl leidenschaftlichen, aber auch toleranten, weil weltläufigen Predigers.

Die Differenz zu Lange lässt sich anhand der Metaphorik des Wanderns schön zeigen. Lange beschreibt die Arbeit an der Predigt als Hin-und-Her-Schreiten auf dem hermeneutischen Zirkel. Das erinnert an das zähe Ringen Jakobs mit dem Flussgott, der ihn erst ihm Morgengrauen ziehen lässt - gesegnet mit dem Einfall, aber auch geschlagen und gezeichnet vom Kampf. Grözingers unaufgeregter Wanderprediger gleicht eher dem Kundschafter, der dem Volk, das in der Wüste wandert, vom verheißenen Land berichtet. Was für den einzelnen ,Milch und Honig' heißen mag und wie die verheißene $\mathrm{Zu}$ kunft aussieht, ist nicht eindeutig - ein vieldeutiges, poetisches Bild, das die Fantasie anregt, ein Bild aus dem biblischen Bilderbuch, das Beheimatung stiften kann. Zu Recht setzt Grözinger stärker auf den Plural der Bilder und Geschichten, als dies Lange tat. Langes Prediger ist ein Anwalt, der den Text für den Hörer verbraucht, Grözingers Prediger ist ein Künstler, der einer hohen Sprachsensibilität bedarf, um Verbindungen zwischen der pluralen Textwelt und den Lebenswelten seiner Hörer herzustellen. 


\subsection{Perspektivenwechsel oder ,Neues Sehen'}

Ein weiteres Plus sehe ich darin, dass das Welten-Modell die Rede von der Lebenswelt als Deutungshorizont pluralisiert, indem es Horizonte verbinden, aber nicht verschmelzen lässt. Die Horizontmetapher wird problematisiert. Sie macht die Differenz vom Eigenen und Fremden zunichte. Sie lässt dem für das Verstehen fundamentalen Perspektivenwechsel von Erkennen und Erkanntwerden zu wenig Spielraum. Die Einspielung dieser Differenz macht es möglich, ein Welten-Modell zu denken und dennoch am Postulat der Einheit der Wirklichkeit festzuhalten, also das Auseinanderfallen in eine lebensweltfreie Gotthälfte und eine gottlose Lebenswelthälfte zu verhindern.

Man kann diesen Gewinn auch mit der Frage verbinden, was sich am Welten-Modell ändert, wenn Wanderer in sich selbst, in der Textwelt oder der Lebenswelt Gott reden lassen. Was erscheint und was verschwindet auf den Weltkarten, wenn man Predigt als Resonanzgeschehen versteht, das auf Anrede reagiert und sich zum Leben Gottes verhält?

Wenn Leben als von Gott gedeutetes und von Gott her bedeutsames Leben in den Horizont rückt, erweitert sich der Horizont der Lebenswelt, durch Wechsel der Interpretationsperspektiven. Dieser Wechsel kehrt die Blickrichtung um und eröffnet neue Spielräume der Weltwahrnehmung. Mit anderen Worten: Predigt schafft Welt. ${ }^{35}$ Kosmisierung ist eine Funktion der Religion. Die neue Welt taucht im klassischen Welten-Modell nicht auf, weil sie entsteht. Man wird sie nicht durch ein Reduktionsverfahren entdecken, weil sie durch die Predigt produziert wird. Das Vorbild der sprachlichen Form, in der sich die neuen Welten erschließen, sind die Gleichnisse Jesu, Metaphern, die einen zwanglosen Perspektivenwechsel bewirken; durch ihre Armut, Anmut und Demut.

\subsection{Zwischenfazit}

Das Bild vom Prediger als Wanderer in und zwischen den Welten dient der Deskription der homiletischen Wirklichkeit. Anders als Lange, der auf Einfall, Einheit und Eindeutigkeit der Rede setzt, die Gott relevant ins Spiel bringen, verlässt sich Grözinger auf die begrenzte Vielfalt des biblischen Kanons und die heilsame Offenheit des Evangeliums, die in der Predigt kunstvoll zusammengehalten wird. Die Pluralisierung der

Vgl. Wilfried Engemann, Predigt als Schöpfungsakt, in: Ders., Theologie, 71-92. 
Wahrnehmungshorizonte ist keine Bedrohung, sondern die Voraussetzung für die Erweiterung des Spielraums homiletischer Deutungspraxis, die immer nur im einen Horizont der Lebenswelt stattfindet. Diese Spannung fordert Kunst regelrecht heraus!

Ich finde das erhellend, plädiere aber dafür, nun auch das WeltenModell nicht zu statisch zu denken. Wenn es um Wirkung und Dynamik der Predigt geht, werden Perspektiven interessant, die innerweltliche - andere gibt es nicht - Gotteserfahrungen machen lassen. Die Perspektive des Glaubens reklamiert keinen anderen Deutungshorizont als den der Lebenswelt, erwartet aber vom Betrachter, dass er sich selbst im Akt des Erkennens als von Gott Erkannter wahrnimmt. Dabei soll nicht der Fehler unterlaufen, für diese Kehre eine Art Gnosis zu proklamieren und für die kommende Welt eine Art Sonderwelt oder Hinterwelt zu reservieren. Wenn Welt als versöhnte Schöpfung und das Ich als befreites Geschöpf wahrgenommen werden, deutet der Interpret seine Existenz im Licht des Kommenden. Dann leuchtet das Göttliche wie ein Wasserzeichen auf. Mehr nicht, aber auch nicht weniger. Die Lebenswelt der Hörer kommt so - durch die Predigt anders und neu in den Blick. Im Perspektivenwechsel des Glaubens ist Gott ein Symbol für die Realität, die Interpretation ermöglicht und deshalb Macht hat, die Deutungshorizonte der Selbstwahrnehmung, der Textwelt und der Lebenswelt zu verschieben. Gott wandert mit. Die Glaubensperspektive stellt alle Welten - auch die Textwelt ${ }^{36}$ - in den Horizont der Welt, die erst noch kommt.

\section{Welten predigen}

\subsection{Das Unscheinbare wahrnehmen}

Nun lädt eine Homiletik, die mit dem Erschließungspotential der kommenden Welt oder neuen Welt rechnet, dazu ein, Großes von der Predigt zu erwarten. Das ist nicht falsch. Problematisch ist hingegen die Erwartung, dass die Präsenz des Göttlichen im Leben großartig und spektakulär sein muss.

36 Mit einer schönen Formulierung von Thomas Klie, Zeichen und Spiel. Semiotische und spieltheoretische Rekonstruktion der Pastoraltheologie, Gütersloh 2003, 346 kann der Prediger die "fremde Welt eines Predigttextes“ nur dann als „eine begehbare und bewohnbare Welt anbieten“, wenn Prediger und Hörer im Heilshorizont lesen und hören. Darum ist die Predigt als religiöse Rede in den Spielraum Gottesdienst eingebettet (siehe 6.). 
Das Gegenteil sei der Fall, erklärt Hans-Günter Heimbrock in seiner Skizze einer phänomenologisch orientierten Homiletik. ${ }^{37}$ Im Anschluss an Gerd Theissens Katalog biblischer Motive nennt Heimbrock die Distanznahme zum Spektakulären und den Hang zum Unscheinbaren ein denkanstößiges Kennzeichen der jüdischen und christlichen Traditionen. ${ }^{38} \mathrm{Um}$ biblische Belege für seine These ist Heimbrock nicht verlegen. Er verweist auf die Gottes-Knechts-Lieder oder die weisheitliche Literatur. Hier zeige sich, wie in der Bezugnahme auf das Unscheinbare heilsame Veränderungen für Mensch und Welt von Gott her angesagt werden. ${ }^{39}$ Thematisch wird das Unscheinbare auch in der Verkündigung Jesu, namentlich in den Gleichnisreden und beim verkündigten Jesus - beispielsweise in der Dialektik dessen, was irdisch im Kreuzgeschehen als unscheinbar und verachtet wahrgenommen wird, und dem, was ins Bekenntnis der Erhöhung des Erniedrigten mündet. ${ }^{40}$

Die Aufgabe der Predigt ist also die Wahrnehmung des Unscheinbaren. ${ }^{41}$ Und die Pointe dieser Wahrnehmung ist die Betonung des sinnlichen Widerstands, der sich dem Glauben bietet, ein Widerstand, der nicht negativ qualifiziert wird. Denn das Niedrige, das Verachtete und Kleine steht für das Verborgene, das im Vorschein des Reiches Gottes mit den Mitteln narrativer Fiktionalität transparent gemacht wird. ${ }^{42}$ Der Leitbegriff ,Wahrnehmung' verweist auf die Leitwissenschaft, mit der die Homiletik operiert - die Phänomenologie.

\subsection{Programm}

Um seinen Ansatz in der Diskussion zu verorten, schließt sich auch Heimbrock Ernst Lange an, würdigt dessen Bemühungen um eine

37 Hans-Günter Heimbrock, Feier des Unscheinbaren. Überlegungen zu Gottesdienst und Predigt, in: Failing/Ders., Gelebte Religion, 177-199.

38 Gerd Theissen, Zeichensprache des Glaubens. Chancen der Predigt heute, Gütersloh 1994, 24f., 29ff. zit. in : Heimbrock, a.a.O., 177.

39 A.a.O., 178.

40 A.a.O., 179.

41 Heimbrocks Einstieg mit Theissens Motivliste provoziert die Rückfrage, warum ausgerechnet dieses Motiv die Aufgabe der Predigt bestimmen soll und nicht die Umkehr, das Gericht oder die Rechtfertigung. Wenn hingegen die Wahrnehmung des Unscheinbaren als eine homiletische Aufgabe begriffen wird, ruft das nach einer Verhältnisbestimmung dieses Motivs zu den anderen Motiven im Gesamt der Verkündigung.

42 Heimbrock, a.a.O., 179. 
„Konzeption der doppelten Wahrnehmungsaufgabe“43 und zieht über diese Begrifflichkeit gewissermaßen eine Linie von der hermeneutischen zur phänomenologisch orientierten Homiletik. In der Einleitung zum Band mit dem programmatischen Titel ,Gelebte Religion wahrnehmen' wird dieses Ziel im größeren Horizont einer praktischtheologischen Wahrnehmungswissenschaft knapp umrissen:

„Praktische Theologie ist zur Erweiterung ihrer wirklichkeitserschließenden Kraft gehalten, neben anderen empirisch-analytischen und handlungstheoretischen Verfahren auch einen phänomenologischen Wahrnehmungsmodus in Gebrauch $\mathrm{zu}$ nehmen ... Ausgangspunkt ist hier die Lebenspraxis zwischen Selbstverständlichkeit und Nicht-Selbstverständlichkeit. Die Arbeit beginnt nicht beim Zugriff auf Wirklichkeit mittels Typisieren und Klassifizieren, nicht bei Faktorenanalysen und Isolierung von Variablen ... Eingesetzt wird vielmehr in der Lebenswelt, bei der Vielfalt von Phänomenen, die sich nicht a priori bestimmen lassen. Gesucht wird nach prägnanten Beschreibungen, die notwendigerweise unvollständig sein müssen, weil mit der Spannung von sich Zeigendem und sich Verbergendem gerechnet werden muss. ${ }^{\text {"44 }}$

Heimbrock markiert eine Fehlstelle in der Theoriearbeit: die mangelnde Aufmerksamkeit für das Unscheinbare. Er ortet diesen Mangel bei verschiedenen homiletischen Konzeptionen, die auf dem Weg zur phänomenologisch orientierten Homiletik gleichsam stecken geblieben sind. Die Quintessenz seiner Kritik lautet: Der außersprachlichen Wirklichkeit wird kein eigenständiges Recht zur Konstitution homiletischer und gottesdienstlicher Situationen eingeräumt. ${ }^{45}$ Auch dort, wo, wie bei Manfred Josuttis oder Henning Luther, die Komplexität menschlicher Wahrnehmungsvorgänge stärker berücksichtigt wurde, werde "die schöpferisch-produktive Komponente homiletischer Arbeit noch zu stark textzentriert gedacht" ${ }^{46}$

Auch in Meyer-Blancks Versuch, Predigen als Anleitung zum ,neuen Sehen' zu verstehen ${ }^{47}$, sieht Heimbrock lediglich die Aufgabe gestellt, aber nicht erledigt. Wo die Wahrnehmung der Wirklichkeit wieder auf die Textarbeit zurückgebogen werde, komme es gerade

\footnotetext{
43 A.a.O., 181-183.
}

44 Heimbrock, Welches Interesse hat Theologie an der Wirklichkeit? Von der Handlungstheorie zur Wahrnehmungswissenschaft, in: Failing/Ders., Gelebte Religion, 11-36, 34 f.

45 Heimbrock, Feier des Unscheinbaren, 184.

46 A.a.O., 187. Heimbrock nimmt Bezug auf Henning Luther, Stufenmodell der Predigtvorbereitung, in: ThPr 17 (1982), 65 und Manfred Josuttis, Dimensionen homiletischer Kompetenz, in: Ders., Rhetorik und Theologie in der Predigtarbeit, München 1985, $47 \mathrm{ff}$.

47 Vgl. dazu Michael Meyer-Blanck, Predigt als ,Neues Sehen'. Zum Verhältnis didaktischer und theologischer Kategorien in der Predigt, in: PrTh 30 (1995), $306 \mathrm{ff}$. 
nicht zur Vermittlung mit dem, was scheinbar unscheinbar vor Augen liege. Die kognitive Umstrukturierung laufe gleichsam ins Leere und die Wirklichkeit verflüchtige sich „zugunsten kollageartig eingebrachter steiler dogmatischer Sätze“ ${ }^{48}$ Es reiche einfach nicht, Vorgänge des neuen Sehens zu beschwören. Eine Theorie des Gottesdienstes müsse vielmehr in noch umfassenderer Weise als bisher zu Wahrnehmungen anleiten.

„Und dazu müsste auch neu gefragt werden, welche homiletisch und liturgisch bislang als unscheinbar eher übersehenen Phänomene in Betracht zu ziehen sind, welche Wahrnehmungshorizonte faktisch für Erleben von und Agieren im Gottesdienst im Spiel sind, und schließlich, welche Reflexionsperspektiven $\mathrm{zu}$ deren angemessener Erschließung taugen können. ${ }^{49}$

\subsection{Sinnliche Wahrnehmung und Sinnstruktur}

Die phänomenologische Erschließung von Wahrnehmungsvorgängen soll also das Verhältnis zwischen Sehen und ,Neuem Sehen' klären und Beziehungen homiletisch fruchtbar machen.50 Das Anliegen einer wahrnehmenden Homiletik, die auf das Unscheinbare achtet, ist primär am Zusammenspiel von Sinn und Sinnlichkeit interessiert. ${ }^{51}$

„Denn wenn religiöse Rede und deren begriffliche Sinnbildung erfahrungsgehaltig bleiben will, muss sie immer auch auf Akte sinnlicher Wahrnehmung wie der Einbildung von Gegenwelten zurückgreifen, um durch sinnliche Wahrnehmung und durch szenische Einbildung nach den Sinn-Gestalten des Evangeliums zu fragen. ${ }^{52}$

Was Aufwertung des Unscheinbaren durch sinnliche Wahrnehmung heißt, verdeutlicht Heimbrock auf dem akustischen Feld - mit der Stimme des Predigers. Die klangliche Gestaltung der menschlichen Stimme sei ein Element der theologischen Botschaft und keine Äußerlichkeit. ${ }^{53}$ Heimbrock warnt allerdings davor, die Wirkungsmöglichkeit solcher außerverbalen Anteile der Wahrnehmung zu überschätzen. Ihm ist wichtig, dass die phänomenologische Haltung zunächst überhaupt auf diese und andere Wirkfaktoren aufmerksam macht. ${ }^{54}$ Das

48 Heimbrock, Feier des Unsichtbaren, 185.

49 A.a.O., 189.

50 A.a.O., 191.

51 A.a.O., 197.

52 A.a.O., 193.

53 A.a.O., 197.

54 A.a.O., 198. Grundlegend sind dazu die Überlegungen vom Maurice Merleau-Ponty. 
Zusammenspiel von Sinn und Sinnlichkeit ist insofern im größeren $\mathrm{Zu}$ sammenhang der Suchbewegung zu sehen, in der die Praktische Theologie im Blick auf die Phänomene der Lebenswelt wieder sprechfähiger werden soll. ${ }^{55}$ Gleiches gilt natürlich auch für Bilder. ${ }^{56}$

\subsection{Anspruch}

Die phänomenologisch orientierte Homiletik macht den Anspruch geltend, über den kritisch-produktiven Zugang zum Leben eine größere Lebensnähe in der religiösen Rede zu erreichen. ${ }^{57}$ Was bei Thurneysen „keine Beredsamkeit!“ und „keine Abwechslung!“ hieß, mündet in vergleichbar apodiktische Postulate: Keine steilen Sätze und keine leeren Hülsen! Positiv ausgedrückt: Wahrnehmung ist Mittel und Zweck - also nicht nur die Vergegenwärtigung von etwas, was zuvor verborgen war, sondern zugleich schöpferische Tätigkeit. ${ }^{58}$ Was auf den ersten Blick eine Methode zur Vorbereitung der Predigthandlung zu sein scheint, ist viel grundsätzlicher. Leben wahrnehmen, darum geht es, wenn Gott kommen soll.

Die phänomenologische Sichtweise ,predigt', indem sie eine Einstellung bzw. einen Wechsel der Einstellung zur Welt vollzieht. ${ }^{59}$ Schon der Blick auf die Lebenswelt ist ein homiletischer Akt. Wer ,Neues

55 Wolf-Eckart Failing/Hans-Günter Heimbrock, Von der Handlungstheorie zur Wahrnehmungstheorie und zurück, in: Dies., Gelebte Religion, 275-294, 275.

56 Ders., Gott im Auge. Über Ansehen und Sehen, in: Failing/Heimbrock, Gelebte Religion, 69-90. Wolf-Eckart Failing legt eine zweite Spur zu einer thematisch gehaltvollen lebensweltlich orientierten Homiletik - gleichsam in Ergänzung zu Heimbrocks Zugang über die Leiblichkeit. Er argumentiert für eine an Alfred Schütz gewonnene Sicht der Lebenswelt. Der Deutungshorizont wird weniger durch die leibhaftige Verbindung der Subjekte mit ihrer Umwelt als durch eine differenzierte Analyse derjenigen intersubjektiven Sinnstrukturen, die im Alltag erzeugt und durch soziale Akte bezeugt werden, gebildet.

57 Failing/Heimbrock, Ansatzpunkte, Perspektiven und Leitbegriffe erneuerter Praktischer Theologie, in: Failing/Heimbrock/Lutz, Religion als Phänomen, 44f. Sehr anregend und lohnend ist ein Seitenblick auf Klaus Kirchhoff, Das gewisse Etwas. Phänomenologische Ansätze in der Religionspädagogik, Berlin/New York 2007. Kirchhoff bietet eine exzellente Zusammenfassung der Phänomenologie (1-97) und findet eine einleuchtende Typologie für die Sondierungsfelder phänomenologischer Ansätze: Leib (158ff.), Alltag (176ff.), Heiliges (193ff.), gelebte und gemeinte Religion (210ff.). Aufschlussreich auch das Kapitel "Wozu sich Phänomenologie nicht eignet". Phänomenologie erschließt nicht das Unmittelbare, fundiert keine Mystik, entdeckt keine religiösen Gehalte und legitimiert keinen Antirationalismus (249-260).

58 Failing/Heimbrock, Von der Handlungstheorie, 285.

59 A.a.O., 293. 
Sehen' will, muss blinzeln, schräg oder indirekt schauen. ${ }^{60}$ Weil diese Einstellung die Handlung begleitet, komme es zu einem Ineinander von Sehen, Urteilen und Handeln. Sinnliche Wahrnehmung wird durch das Abschreiten von Sinnhorizonten zum Sinnverstehen und trägt nicht nur äußerlich zur Sinnbildung bei. ${ }^{61}$ Und weil dadurch Verstehen, Normieren und Handeln „nicht mehr sauber getrennt" werden, überrascht es nicht, dass Failing und Heimbrock in ihrem Ausblick formulieren, "dass Ästhetik und Ethik [...] in eine neue Gemengelage kommen, die sich bisherigen Entgegensetzungen entzieht, denn Wahrnehmen ist auch als Gestalten zu begreifen." ${ }^{\prime 62}$

\subsection{Anregung}

Aus dieser "Gemengelage" auf der Ebene der homiletischen Praxistheorie die richtigen Schlüsse zu ziehen, ist nicht einfach. Und es ist auch nicht immer klar, wo Phänomenologie, Praktische Theologie und Homiletik ineinander übergehen. Eines scheint aber unbestritten: Durch ihre Lebensnähe wird die Frage, wie ich in der Predigt mit dem Hörer über sein Leben reden kann, zur permanenten Such- und Reflexionsbewegung, die nicht mit dem Predigteinfall ihren Abschluss findet, sondern in der Predigt gegen falsche Unmittelbarkeit protestiert, für produktive Störungen offen ist und auf dem Offenhalten der Erfahrung des Religiösen insistiert. ${ }^{63}$

Da sehe ich das Plus dieses Ansatzes: Eine phänomenologisch orientierte Homiletik übersetzt das Leben nicht, sondern will den Prediger mitsamt seinem theologischen Interpretationsapparat und seinen Texten in die Welt seiner Hörer versetzen. Predigen ist reden mit dem Leben seiner Hörer. Denn in der gehaltvoll verstandenen Lebenswelt trifft der Prediger nicht nur auf den Widerstand gegen die Verheissung, sondern auch auf Nischen des Heiligen und Unheiligen, Zwischenräume und Zwischenböden für gelebte Religion, z. B. in der Mediengesellschaft. ${ }^{64}$ Darum wird der Feldherrenblick der Offenbarungstheologie durch die Quersicht eines Predigers ersetzt, der sich von dem überraschen lässt, was sich ihm in der Lebenswelt der Hörer gehaltvoll

60 Oder mit Lévinas, Die Spur des Anderen, 87: „Phänomenologie betreiben heißt, die direkte Sicht des Gegenstandes als naiv zu denunzieren."

61 A.a.O., 283.

62 A.a.O., 282.

63 Failing/Heimbrock, Ansatzpunkte, 43.

64 Vgl. dazu Wilhelm Gräb, Sinn fürs Unendliche. Religion in der Mediengesellschaft, bes. Predigt als religiöse Rede in der Mediengesellschaft, $294 \mathrm{f}$. 
zeigt. Die Predigerin ist auch nicht die Anwältin des angefochtenen Hörers, weil sie die Lebenswelt als umfassenden, transzendentalen und universal gedachten Deutungshorizont erfährt, in der Welt, in der sie Religion erlebt und zu der sie sich verhält.

Durch den erweiterten und gefüllten Lebensweltbegriff kann eine weitere Verengung korrigiert werden. Wenn vom ,Verhalten' und vom ,Erleben', also von nicht verfügbaren Einbezogenheiten ausgegangen wird, verbietet sich eine funktionalistische Reduktion der Religion auf Krisenbearbeitung im Lebenszyklus. ${ }^{65}$ Damit sind wir auch am Kern dessen, was der Leitbegriff ,Leben' leisten soll. Er sichert den umfassenderen Auslegungshorizont über institutionell verfasste Religiosität hinaus und er sichert „,in einer praktischen Religionsforschung das Elementare wie das Ambivalente und das Irrationale ${ }^{\prime \prime 66}$ der Religion in der Spannung zwischen Bestimmtheit und Unbestimmtheit des Alltags.

\section{Lebenswelt als Deutungshorizont der Predigt - ein Klärungsversuch}

\subsection{Klärungsbedarf}

Die Phänomenologie - so viel finde ich einleuchtend - offeriert einen methodisch reflektierten Weg zum Leben, auf dem einerseits Wirklichkeitsdimensionen mit Wahrheitsperspektiven und andererseits Beschreibungsvollzüge mit Deutungsakten verbunden werden. In pointierter Weise bringen Failing und Lotz in der Einführung zum Band ,Religion als Phänomen' auf den Punkt, warum sie die phänomenologische Orientierung für „ein durchgängiges Grundverständnis von Wissenschaft, Wirklichkeit und Wahrheit" ${ }^{\text {"67 }}$ halten oder mit anderen Worten einen Deutungshorizont reklamieren. Phänomenologie wird als eine Reflexionsweise in Anspruch genommen, die „lebensweltliche Strukturen des Handelns, leiblichen Verhaltens, Wahrnehmens und Denkens als Fundament sowohl alltäglicher als auch wissenschaftlicher Sichtweisen menschlicher Existenz und der Wirklichkeit aufzuweisen bemüht ist." ${ }^{68}$

65 Failing/Heimbrock, Ansatzpunkte, 44.

66 Ebd.

67 Failing/Heimbrock/Lotz, Religion als Phänomen., 6 (kursiv).

68 A.a.O., 3. 
Das unverkennbare Pathos der Lebensnähe - so viel ist ebenfalls klar - will Einfluss nehmen durch das, was einfließt, und einen Einstellungswechsel erreichen, Routinen brechen, sich überraschen lassen von den Anfängen. Denn ...

"[...] die Lebenswelt im strikt phänomenologischen Sinn ist ja nicht ein anderes Wort für Konkretion, sondern die Rede von der Lebenswelt verweist auch die Praktische Theologie vor allem auf die Welt des beginnenden Auseinanders, der Augenblicke des Übergangs von der Einheit zur Zweiheit, wo Handeln, Erkennen, Anschauung und Begriff, Bedeutung und Zeichen alles noch ineinander und doch schon dabei ist dort, wo es sich voneinander löst. "69

Diesen Übergang in der einen Wirklichkeit zu finden, ist die erklärte Absicht. So viel ist klar. Klärungsbedürftig bleibt, ob und wie sich dieser „Übergang von der Einheit zur Zweiheit“ mit einer phänomenologischen Dauerreflexion ${ }^{70}$ überhaupt finden lässt.

\subsection{Beschreibende Phänomenologie oder was meint die Rede über das Leben}

Ist denn die Phänomenologie eine Art Lebenskunde, die Leben, das im Übergang gefunden wird, verkündigt? Oder doch nur beschreibt? Michael Moxter gibt darauf eine sehr dezidierte Antwort und lässt mich zu dem eingangs notierten Paradox zurück kommen, wenn er sagt: „Zu den Sachen selbst! Ist [...] eine Devise, die auf die Beschreibung von Phänomenen zielt. “" ${ }^{\prime 1}$ Diese Devise stehe in Kontrast zum Erklären, Typisieren und Klassifizieren. Das Leitmotiv müsste eigentlich lauten: "Nicht nur zu den Sachen selbst, sondern auch nie von den Sachen weg." 72 Phänomenologie, sagt Moxter, „beginnt jenseits von Realismus und Idealismus (wie Lévinas sagen würde), von Sache selbst und subjektiver Setzung" und setze insofern einen veränderten Begriff von Wirklichkeit in Kraft. Das Grundproblem der Phänomenologie sei daher die Frage, „welchen Status Beschreibungen dessen, was sich zeigt, im wissenschaftlichen Diskurs haben können oder sollen. ${ }^{\text {73 }}$

\footnotetext{
69 A.a.O., 4.

70 In Anlehnung an Schelskys „instiutionelle Dauerreflexion“, auf die Ernst Lange sich verschiedentlich bezogen hat.

71 Michael Moxter, Die Phänome der Phänomenologie, in: Failing/Heimbrock/Lotz, Religion als Phänomen, 85-95, 91.

72 Moxter, a.a.O. zitiert Lévinas, Die Spur des Anderen, 1983, 55.

73 A.a.O., 92.
} 
Der Status sei prekär, weil die Beschreibungsdevise quer zum argumentativen Diskurs stehe. Die Phänomenalität des Phänomens sei nämlich nicht gegeben. Die Beschreibung bleibe notwendig unvollständig, weil sich das, was sich zeigt, immer nur auf dem Hintergrund dessen zeigt, was sich nicht zeigen lässt. Die philosophische Tugend „liegt in der Offenheit der erneuten Rückfrage, ob die Phänomene sich wirklich so zeigen, wie bisher gemeint", weil es beim Sehen immer auch um die Präsenz dessen geht, was nicht zu sehen ist. ${ }^{74}$ Die Rückkehr zu den Sachen sei zugleich Rückkehr zu den sie konstituierenden Aktvollzügen. ${ }^{75} \mathrm{Im}$,Zugang' ist darum zwingend auch ein ,Zurück' zur Sprache gegeben. Die unvollständige Beschreibung löst neue Erkundungen aus.

Um die sprachliche Rückbindung der Vorstellung eines Phänomens im Denken des Interpreten begrifflich anzuzeigen, spricht ein anderer Phänomenologie-Theoretiker, Hermann Deuser, von einer semiotischen Phänomenologie und unterscheidet diese von der begründenden und beschreibenden. Alle Lebensvollzüge sind semiotisch konstituiert. Was ein Phänomen ist, folgt demnach aus den Wirklichkeitsbezügen aller Zeichenprozesse. Die Quintessenz einer semiotisch formulierten Phänomenologie bringt schließlich Ingolf Dalferth auf den Punkt, wenn er definiert:

„Ein Phänomen ist ein Akt lebensweltlichen Verstehens im Horizont einer eingespielten Verstehenspraxis. Dieser Akt ist zugleich wirklichkeitsinformiert und wirklichkeitsinterpretativ. Das heißt, er lässt sich als lebensweltlicher Interpretationsakt interpretieren, indem in der Einheit eines Vorgangs etwas für jemand als etwas erscheint und von jemand durch etwas als etwas für jemanden interpretiert wird. ${ }^{\text {"76 }}$

Die semiotische Definition des Phänomens macht noch einmal die Pointe der nachmetaphysischen Weltsicht stark: Es gibt keine Wirklichkeit hinter den Phänomenen, denn nur was wirklich ist, kann interpretiert werden, und nur durch Wirkliches wird etwas interpretiert. Phänomene treten für jemanden, hier und jetzt, stets im Übergang zu anderen Phänomenen und immer in Perspektiven und Horizonten einer Interpretationspraxis in Erscheinung. Erst in der phänomenologischen Reflexion werden Phänomene als Phänomene wahrgenommen. Damit wird die selbstverständliche Gewissheit unserer Weltwahrnehmung, dass das, was wir wahrnehmen, wirklich so sei,

\footnotetext{
74 A.a.O., 93.

75 A.a.O., 94.

76 Ingolf Dalferth, Die Wirklichkeit des Möglichen. Hermeneutische Religionsphilosophie, Tübingen 2003, 128.
} 
wie wir es wahrnehmen, problematisiert, aber nicht gänzlich in Abrede gestellt. Phänomenologische Beschreibungen machen deutlich, was für alle Beschreibungen gilt: „,... dass Phänomene stets in einer Perspektive und damit in einem bestimmten Horizont wahrgenommen werden. ${ }^{\text {"77 }}$ Auch dort, wo wir meinen, es mit den Sachen selbst zu tun zu haben, erfassen wir das Phänomen nur „im Bestimmungshorizont einer Zeichen- und Interpretationspraxis“. ${ }^{78}$ Es gibt kein Phänomen ohne Horizont. Es ist nur in ihm und mit ihm zusammen Phänomen. Das heißt aber nicht, dass der Horizont das Phänomen bestimmt. Denn Horizonte lassen sich perspektivisch verschieben. Um unterschiedliche Phänomenbeschreibungen $\mathrm{zu}$ vergleichen, müssen deshalb die Perspektiven thematisiert werden, die Interpretationshorizonte erzeugen.

\subsection{Pragmatische Phänomenologie oder: wozu reden wir über Leben?}

Perspektiven lassen sich auf verschiedenen Ebenen einnehmen/anwenden? Von daher erschließt sich, was mit der Formel „Lebenswelt als Deutungshorizont" gemeint ist und was nicht gemeint sein kann.

„In lebensweltlichen Perspektiven, die zum Lebensvollzug gehören, kommen bestimmte Phänomene im Vollzugshorizont der Partizipianten in den Blick. Davon unterschieden sind Perspektiven auf einen Lebensvollzug aus der Position eines Beobachters, der Phänomene im Beschreibungshorizont als etwas für andere beschreibt und den Perspektiven, die Beschreibungen als Beschreibungen in einem Theoriehorizont an weitere Beschreibungen anschließen lassen. "79

Phänomene werden im Horizont einer Welt variiert, weiter bestimmt und interpretiert, die sich im Vollzugshorizont als Lebenswelt, im Beschreibungshorizont als Phänomenwelt und im Theoriehorizont als Möglichkeitswelt differenziert bestimmen lässt. Die Semiotik liefert lediglich die erkenntnistheoretische Basis, auf der die religionsphilosophische Frage, wie Gott in der sprachlichen Rückbindung als Symbol vorkommt und dem Denken zuvorkommt, bedacht werden kann.

\footnotetext{
77 A.a.O., 131.

78 A.a.O., 130.

79 Dalferth, Die Wirklichkeit des Möglichen, 131.
} 
Näher an der Lebenspraxis, weil sie Orientierung verspricht, ist für die Predigt die Frage, wozu Gott zum Zug kommen soll. ${ }^{80}$ Die Antwort auf diese Frage entscheidet über die Richtung, die eine Predigttheorie nimmt, also darüber, ob sie stärker hermeneutisch, phänomenologisch oder kerygmatisch ausgerichtet ist. Um keine Missverständnisse aufkommen zu lassen: Richtungen sind kein Richtigkeiten. Homiletische Theorie und Praxis, die einen gehaltvollen Lebensweltbegriff verwenden, werden auf eine phänomenologische Perspektive nicht verzichten. ${ }^{81}$ Genauso richtungsweisend ist es aber, die Lebensnähe und den Lebensbezug einer Predigt im Zusammenhang ihrer erhofften und erwarteten Wirkung zu sehen. ${ }^{82}$ Die Predigt ist phänomenologisch als Rede zu beschreiben, in der die Anrede Gottes erfahren werden soll. Daher ist, so Karl Barth, Predigt als Ankündigung dessen zu verstehen, "was sie [die Hörer] von Gott selbst zu hören haben." ${ }^{\text {" }}$

Schliesslich besteht die hermeneutisch gerichtete Homiletik darauf, dass aus Ankündigung der Verkündigung nicht die Verkündigung der Ankündigung wird, indem sie den Plural möglicher Wirkungen stark macht. Predigten können erschüttern, verzaubern, bekehren, wecken, beruhigen und trösten. Die kerygmatische Homiletik ihrerseits betont, dass die Wirkung der Rede im Leben des Hörers dem Leben, das in Gottes Namen angenommen und anerkannt wird, zu verdanken sei. Die Predigt kreiert eine Sprachwelt, die der Bewegung zur Schwelle nachfährt - eine Erfahrung mit der Erfahrung dieser Gottesrede im Gottesdienst machen lässt - um so auf Gott zurück zu kommen. Pragmatisch ist das Ziel der Predigt dadurch bestimmt, dass die Hörer wieder etwas mit Gott anfangen können. Ernst Lange hat es auf seine Weise so ausgedrückt: Der homiletische Akt lässt Christus wieder „Herr der Situation“ sein. Ich erinnere auch an das Votum Luthers, dass der Lebensbezug der Homiletik Christus zum fundamentum in re hat. ${ }^{84}$ Insofern kennt die Auslegung der Lebenswelt, wie die Schriftauslegung, das Prinzip , was Christum treibet'.

80 Vgl. dazu Schröer, a.a.O., 57, der die konstitutive Bedeutung der Frage nach dem Wo? und dem Wohin? hervorhebt. Damit werde das „oft sterile Spiel von Inhalt und Form, Was und Wie, situativ pragmatisch" aufgehoben.

81 Moxter, a.a.O., 95.

82 Vgl. dazu Frank Michael Lütze, Absicht und Wirkung der Predigt. Eine Untersuchung zur homiletischen Pragmatik, Leipzig 2006. Ausgehend vom Handlungscharakter des Wortes Gottes (22ff.) entwirft Lütze das Handlungsprofil des Rechtfertigungsgeschehens als das Ende des infiniten Spiels der incurvatio in seipsum durch die Erfahrung der Liebe Gottes (56).

83 Karl Barth, Homiletik, Zürich 1970, 30.

84 Siehe oben 1.2 Anm. 8. 
Von der Interpretationsperspektive des Glaubens her betrachtet, scheint es mir deshalb fragwürdig, die phänomenologische Orientierung der Praktischen Theologie konkurrenzlos als "durchgängiges Grundverständnis von Wissenschaft, Wirklichkeit und Wahrheit ${ }^{\prime 85} \mathrm{zu}$ propagieren. Im Lichte dessen, was in der Predigt geschieht manchmal geschehen darf -, spricht viel dafür, die kerygmatische Orientierung der Praktischen Theologie als durchgängiges Grundverständnis von Wissenschaft, Wirklichkeit und Wahrheit anzunehmen. Es steht aber nicht der Ausschluss der phänomenologischen, sondern das hermeneutisch reflektierte Verhältnis der theologischen zur phänomenologischen Orientierung zur Debatte. Denn von dieser Verhältnisbestimmung hängt einiges $a b .{ }^{86}$

\subsection{Gelebte Religion und Glaube oder die Frage, wo Leben ist}

Ich zweifle nicht daran, dass die phänomenologische Orientierung der Konstituierung der Praktischen Theologie wichtige Impulse gegeben hat. Aber ich bin skeptisch, ob ,gelebte Religion' zur Leitbegrifflichkeit taugt, mit der die „inhaltliche Einheit der Praktischen Theologie als Wissenschaft ${ }^{\prime \prime 8}$ neu bestimmt werden kann. Anders als Failing und Heimbrock und mit Henning Schröer halte ich die "Verhältnisbestimmung von gelebter Religion und gelebtem christlichen Glauben" 88 für einen Schlüssel bei der Suche nach der inhaltlichen Einheit der Wirklichkeit. ${ }^{89} \mathrm{Im}$ Unterschied zu den Kulturwissenschaften

85 Failing/Heimbrock/Lotz, Religion als Phänomen, 6 (kursiv).

86 Zum Beispiel, wie man die Funktion der Theologie in Bezug auf die Kirche denkt! Vgl. dazu Hans-Martin Rieger, Theologie als Funktion der Kirche, Berlin 2007. Rieger stellt Wilhelm Gräbs religionstheologische Kulturhermeneutik, die ihren Gegenstand in der gelebten Religion sieht, der Theologie Ingolf U. Dalferths gegenüber. Es geht auch um das Verhältnis einer philosophischen Phänomenologie, die die Möglichkeit des Wirklichen beschreibt, zur Theologie, die die Wirklichkeit des Möglichen als sprachlich vermittelte Wirklichkeit Gottes zum Ausgangpunkt des Nachdenkens über den Glauben erklärt.

87 Vgl. dazu Albrecht Grözinger/Jürgen Lott (Hg.), Gelebte Religion. Im Brennpunkt praktisch-theologischen Denkens und Handelns, Rheinbach-Merzbach 1997, 12. Zitiert in: Failing/Heimbrock/Lotz, Religion als Phänomen, 36.

88 Henning Schröer, Die Bedeutung der Phänomenologie für die Konstitution Praktischer Theologie, in: Failing/Heimbrock/Lotz, Religion als Phänomen, 46-59, 54.

89 Failing/Heimbrock, Religion als Phänomen, 37 diskutieren das Verhältnis von Glauben und Religion und vertreten eine differenzierte Position. Einleuchtend daran finde ich, dass gelebte Religion nicht synonym zu gelebtem Glauben (vgl. Trillhaas, Religionsphilosophie, Berlin 1972, 19) verstanden werden kann. Problematisch ist auch eine kontextuelle Einschränkung der Praktischen Theologie auf die spezifische 
oder zur Religionsphilosophie versteht die Theologie den Glauben auch, aber nicht nur als kulturelles Faktum. Sie geht zwar auch von der Wirklichkeit des gelebten Glaubens aus, „versteht den Glauben aber von vornherein als Werk und Wirkung Gottes (factum dei), indem sie die Wirklichkeit des Glaubens und seine Sicht der Wirklichkeiten der Welt im Licht der von Gott eröffneten Möglichkeiten versteht und entfaltet, von denen der Glaube selbst bekennt, dass er sich ihnen verdankt. " $" 90$

Das theologische Verständnis des Glaubens hält mit Ingolf Dalferths Kurzformel ausgedrückt an der Wirklichkeit des Möglichen fest, folgt dabei der Selbstauslegung des Glaubens, ohne in die oben erwähnte endlose Schlaufe oder in einen hermetischen Zirkel zu fallen. Denn im Hin und Her zwischen Welt und Gott gewinnen die Interpretationen an Bedeutung. Die Wahrnehmung der Wirklichkeit erfüllt sich, gewinnt an Gewicht und Glanz, wenn sie die Welt im Horizont der kommenden Basileia interpretiert. Theologie spricht vom Sinn des Glaubens im Horizont des Glaubens - sie bringt ihn in der Perspektive der Glaubenden und in deren Deutung als gottverdankte Möglichkeit und Wirklichkeit zur Sprache. Theologie bringt daher auch die Perspektiven der zweiten und dritten Person vom Standpunkt der ErstPerson-Perspektive eines Beteiligten ins Spiel. Nicht-religiöse Gesichtspunkte werden in eine religiöse Perspektive gerückt. ${ }^{91}$

\subsection{Gott oder die Frage, woher das Leben kommt}

Jede Wahrnehmung von Wirklichkeit ist perspektivisch. Im Unterschied zu einer philosophisch-phänomenologischen Betrachtung der Welt, die immer nur innerhalb eines Welthorizonts operiert, stellt Theologie aber die Perspektive, in der sie denkt, deutet und urteilt, ausdrücklich klar, indem sie „von Gott als Schöpfer, Erlöser und Vollender spricht. ${ }^{\prime \prime 2}$ Bezogen auf die Aufgabe der Predigt: diese kategoriale

Lebenswelt des Glaubens oder eine ethische Beschränkung der Lebenswelt als Bewährungskontext des Glaubens (vgl. Härle, Dogmatik, Berlin/New York 1995, 168ff.). Die Identifikation von gelebtem Glauben und gelebter Religion, die Ausblendung und die normative Überblendung der gelebten Religion werden zu Recht kritisiert. Welche Funktion die gelebte Glaubenspraxis im Gegenüber zu einer prinzipiell offenen Religionspraxis konstruktiv und kritisch haben kann, bleibt aber ungeklärt.

90 Dalferth, Wirklichkeit des Möglichen, 108.

91 Ich folge hier weitgehend Dalferths Überlegungen ohne jeden Gedanken im Einzelnen auszuweisen.

92 A.a.O., 119. 
Unterscheidung der Interpretationsperspektiven coram mundo und coram deo relativiert die Rede von der Lebenswelt als Deutungshorizont, weil die Kehrtwende des Glaubens die Welt nicht nur neu, sondern auch ganz anders sehen lässt (2.3.2).

Dass theologisch nicht nur von Welt, sondern von Schöpfung, nicht nur von Menschen, sondern von gerechtfertigten Sündern und Geschöpfen, nicht nur von Gott, sondern vom Schöpfer, Erlöser und Vollender gesprochen wird, zeigt an, dass die coram deo-Perspektive nicht als kontinuierliche Fortbestimmung der coram mundo-Perspektive, sondern als Bruch mit ihr erscheint. ${ }^{93}$ „Theologie thematisiert also nichts anderes als Wissenschaft und Philosophie, aber sie thematisiert es in einer anderen Interpretationsperspektive: nicht im Welthorizont des Wirklichen oder Möglichen, sondern im Möglichkeitshorizont von Gottes Wirken als Schöpfer, Erlöser und Vollender." ${ }^{\prime 94}$

Die Deutung der Welt coram deo ist darum mehr als eine kritische Begleitung der gelebten Religion. Sie entfaltet ein bestimmtes praktisches Orientierungswissen im Horizont der Unterscheidung von Möglichem und Unmöglichem. Denn „nach theologischem Urteil ist Wirkliches nicht nur das, was es faktisch ist, aber auch nicht nur das, was es angesichts dessen, was es faktisch ist, auch noch hätte sein können, sondern vor allem das, was es als faktisch Wirkliches mit seinem Horizont von Möglichkeiten coram deo und damit nach Einsicht des Glaubens in seinem gottverdankten Existenz- oder Lebensspielraum in Wahrheit ist: Schöpfung Gottes. ${ }^{\prime 95}$

Mit der Spielraummetapher ist angezeigt, dass durch den Gottesbezug auf das Wirkliche die Differenz zwischen der faktischen Wirklichkeit und der wesentlichen Wahrheit etabliert wird.

"Gott ist kein ausgezeichneter Fall von Wirklichem und/oder Möglichem, sondern nichts ist möglich oder wirklich ohne Gott. “96

Gott ist demnach kein Grenzbegriff der Welt, sondern erschließt sich im theologischen Urteil im Horizont seines Gottseins als Offenbarung. ${ }^{97}$

Der Ort, an dem dies explizit und kunstvoll geschieht, ist der Gottesdienst. Die Liturgie ist Spielraum für die Wirklichkeit des

\footnotetext{
93 A.a.O., $126 f$.

94 A.a.O., 127.

95 A.a.O., 119.

96 A.a.O., 124.

97 A.a.O., 125: „Gottes Gottsein, das ist die Pointe der christlichen Inkarnationsmetapher, erschließt sich vielmehr durch das Wirken des Geistes Gottes in Auferweckung und Menschwerdung Jesu Christi auch für andere als selbstlose Liebe zu seinen Geschöpfen und ist dementsprechend theologisch von dort aus zu denken."
} 
Möglichkeit par excellence: nicht im Sinne einer Exklusivität, sondern beherzt inklusiv und konklusiv. Der gelebte Glaube, der sich in der Sendung bewährt, wird reflektiert im gefeierten Glauben, der das Geschenk des Lebens empfängt.

\section{Mit Gott zu Gott von Gott reden}

Ich ziehe ein Fazit. Eine phänomenologisch orientierte Theologie beharrt auf der Differenz von Gott und Welt, indem sie sich wehrt und verwahrt gegen eine ausschliesslich normative Differenz von Leben und ,wahrem Leben' ${ }^{98}$ Daran ist richtig, dass die Phänomenologie nicht auf eine "Vorstufe sensibler Erkundung im Dickicht des Alltags", reduziert werden soll, ,,um sodann in einem oder mehreren Schritten andere und neuere Methodologien einzuführen bzw. vermeintlich theologisch zu werden. " 99 Genauso wichtig ist es, mit der Wahrnehmung der Lebenswelt auch eine Kritik am scheinbar vorgegebenen und reinen Glauben $\mathrm{zu}$ verbinden. ${ }^{100}$ Praktische Theologie interessiert sich für gelebte Religion, weil sie den Hintergrund bildet, vor dem sich "thematisch so etwas wie Geist, neues Leben abhebt" ${ }^{\prime \prime}{ }^{101}$

Wenn aber der Praktischen Theologie nur die Aufgabe zugewiesen wird, „Bedingungen und Möglichkeiten gelebter Religion in der Lebenswelt zu erkunden, kritisch im Sinne christlicher Wahrheitssuche $\mathrm{zu}$ begleiten und behutsame Anregungen $\mathrm{zu}$ geben für ihre Kultivierung und Gestaltung “102, ist das zu wenig; dann wird der Perspektivenwechsel des Glaubens der phänomenologischen Orientierung untergeordnet. Dann werden die Kehrtwenden, die im Gottesdienst vollzogen werden, nur immer als mögliche Sichtweisen, aber nicht als wirkliche Möglichkeiten traktiert. Gäbe es nur "Wahrheitssuche“, bliebe der Zusammenhang zwischen Wahrnehmung und Kritik in einer entscheidenden Hinsicht unterbestimmt:

In der spannungsvollen Korrelation zwischen gelebter Religion und Glauben muss die Praktische Theologie das Maß auch an der Wahrheit des Glaubens nehmen. Gerade nicht, um reine Lehre zu treiben, sondern, um Erkenntnis und Bekenntnis im Anerkennen zu

98 In kritischer Abgrenzung von Gerhard Ebeling, Dogmatik des christlichen Glaubens, Bd. I, Tübingen 1979, 79f. zit. in: Failing/Heimbrock, Ansatzpunkte, 45.

99 Failing/Lotz, Ausgangspunkt, 6.

100 Failing/Heimbrock, Ausblick, 294.

101 Failing/Lotz, Ausgangspunkt, 4.

102 A.a.O., 3. 
korrelieren. ${ }^{103} \mathrm{Ob}$ man das Resultat dieser Verschränkung dann wiederum gelebte Religion oder gelebten Glauben nennen will, ist nicht entscheidend. Wichtig finde ich, dass Theologie, die Religion kritisch begleitet, nicht aus der Gläubigkeit verabschieden kann. ${ }^{104}$ In diesem dialektischem Sinn bildet der Glaube den Horizont, in dem sich Religion gehaltvoll deuten lässt. Die Unterscheidung von Religion und Glauben soll nicht in ein Entweder-Oder führen. Sie interpretiert vielmehr den Wechsel der Perspektive, der sich in der Predigt ereignen soll, gottesdiensttheologisch. Die Theorie der Predigt reflektiert den Wechsel und hält dem, der predigt, einen Spiegel vor, damit der seine eigene Praxis bedenken und befragen kann. Wenn der Prediger darauf aus ist, so zu reden, dass das Evangelium in der Lebenswelt der Hörer ankommt, dann muss er den zuversichtlichen und den angefochtenen Glauben miteinander ins Gespräch bringen.105 Er spricht dann manchmal in der dritten Person eines Erzählers von der Welt oder übernimmt das, wir' der communio sanctorum oder wagt es, das göttliche Ich auszuleihen. Jede dieser Rollen, die poetische, priesterliche und die prophetische birgt das Risiko in sich, dass der Prediger über die Köpfe hinweg statt über das Leben der Menschen redet.

Aber Predigen wäre verkürzt wahrgenommen, wenn es nur als ein Reden mit dem Hörer oder mit den Sachen und nicht auch als ein Reden verstanden würde, das mit Gott - mit Gott zusammen - zur Sache kommt. Predigt bleibt Kunst. ${ }^{106}$ Nur geschieht diese Kunst unter der Voraussetzung, dass sich Gott am Gottesdienst beteiligt. ${ }^{107}$ Die ars praedicandi wird von der ars celebrandi gehalten. Reden mit Gott ist eingebettet in das Reden zu Gott. Als Glied der Kirche ist die Predigerin mitgetragen von der betenden Gemeinde und mitbeflügelt vom Geist, der in der Liturgie weht. Wer predigt, singt und bekennt, betet und

$103 \mathrm{Zu}$ dieser Trias vgl. Karl Barth, KD IV, 840.

104 Diese Unterscheidung findet sich bei Dietrich Bonhoeffer, Akt und Sein. Transzendentalphilosophie und Ontologie in der systematischen Theologie, hrsg. von HansRichard Reuter, in: Eberhard Bethge (Hg.), Dietrich Bonhoeffer. Werke, Bd. 2, München, 1986, 153f. Eine kritische Untersuchung bietet Hans Friedrich Daub, Die Stellvertretung Jesu Christi. Ein Aspekt des Gott-Mensch-Verhältnisses bei Dietrich Bonhoeffer, Berlin 2006, bes. 276-278.

105 Zum komplexen Situationsbegriff von Ernst Lange vgl. Jan Hermelink, Die homiletische Situation. Zur jüngeren Geschichte eines Predigtproblems, Göttingen 1992.

106 Bei allen Gegensätzen scheint das der Konsens zu sein. Vgl. Gräb, Sinn fürs Unendliche, 309-312, 311.

107 Vgl. dazu die fulminante Studie von Matthew Myer Boulton, God against Religion. Rethinking christian Theology through Worship, Grand Rapids (MI)/Cambridge (UK) 2008, bes. 161-194. 
segnet im Sinn und Geist der Schrift. Aufgabe der Predigt ist es, gelebte Religion im Deutungshorizont des gefeierten Glaubens nicht nur beobachtend, sondern beteiligt darzustellen. Und diese Beteiligung wird im homiletischen Sprechakt spürbar, erlebbar und nachvollziehbar als reden mit Gott zu Gott und von Gott. Vielleicht werden Predigten lebendiger, wenn sich die Prediger nicht als Lebensretter vorkommen!? 
